\title{
MODERN TECHNOLOGIES INFLUENCE ON PROJECT SUCCESS FACTORS IN IT SECTOR OF SERBIA
}

\author{
UDC: 005.8:004(497.11) \\ Original Scientific Paper \\ Tamara ZORIĆ ${ }^{1}$, Vesna MAKITAN ${ }^{2}$, Eleonora BRTKA ${ }^{3}$, Simo MRĐEN $^{4}$ \\ ${ }^{1}$ Vega IT sourcing, 21000 Novi Sad, 2, Novosadskog sajma, Republic of Serbia \\ ${ }^{2}$ University of Novi Sad, Technical faculty “Mihajlo Pupin” in Zrenjanin, 23000 Zrenjanin, Đure Đakovića bb, \\ Republic of Serbia \\ E-mail: vesna@tfzr.uns.ac.rs \\ ${ }^{3}$ University of Novi Sad, Technical faculty “Mihajlo Pupin” in Zrenjanin, 23000 Zrenjanin, Đure Đakovića bb, \\ Republic of Serbia \\ ${ }^{4}$ Republic of Serbia
}

Paper received: 24.10.2021.; Paper accepted: 22.11.2021.

\begin{abstract}
Given the technological advances and the recognized importance of the application of technologies in project management, the question arises whether the technologies of Industry 4.0 can solve the problem of failure of information technologies (IT) projects. This question is the main motivator for writing this paper and conducting research on this topic. This paper describes a research that was conducted with the intention of examining the extent to which modern technologies can contribute to the success of IT projects. The research shows the extent to which modern technologies are applied in project management in the IT sector of Serbia, as well as the extent to which experts believe that these technologies have a positive impact on project success, analyzing the issue through their impact on success factors. This research provides insights that can contribute to a better understanding of modern technologies and their application in practice.
\end{abstract}

Keywords: IT projects; IT project management; Project success factors; Industry 4.0 technologies.

\section{INTRODUCTION}

As the literature and practice recognize that technological progress has a great impact on the field of project management, the motivation for conducting research aimed at examination of impact of modern technologies of Industry 4.0 on the field of IT project management arose. The reason why the subject of research is focused on modern technologies lies in the recognized impact that these technologies have on the project success. Given that IT projects are recognized in practice and in the literature as projects that are likely to fail, examination of impact of modern technologies on the issue of success can identify new ways to change this practice and contribute to project success. From the aspect of this paper, cloud, Internet of Things (IoT) and artificial intelligence (AI) technologies are considered modern technologies, with the intention to examine their application in the management of IT projects in Serbia.

The research was conducted with the primary objectives to examine the extent to which modern technologies are applied in the field of project management in the IT sector of Serbia, as well as the extent to which experts in this field believe that modern technologies affect project success factors. Examination of these two issues provided a better understanding of the current state of practice in the field of IT project management, as well as new knowledge that will provide the necessary guidance in the selection of modern technologies. With these results, the research has provided a scientific contribution that is reflected in the expansion of literature in the field of IT project management.

This paper is structured in several segments. The first segment of the paper provides a theoretical 
overview concerning issues of interest. This segment generally considers the current status of research in the field of project management, where special attention is paid to the issue of technologies application. The next segment of the paper provides an overview of the conducted research. This segment presents the important aspects of conducted research, such as the subject and goals of research, the set hypotheses, as well as the methods, techniques and instruments on which this research is based. The next segment provides research results and analysis of the obtained results. The results were initially analyzed from the aspect of demographic data, in order to see the structure of the sample itself. After that, the results are analyzed separately, which are based on the use of technologies, success factors and success criteria. The discussion of the paper is the last chapter in which the results of the paper are viewed from the perspective of set issues. The set hypotheses are examined and conclusions are made based on the research results.

\section{RELATED WORK}

Organizations still face the problem of choosing a methodology from the aspect of modern or traditional. Although traditional project management methodologies are well-established, developed over a long period of time, they no longer seem to be sufficient to overcome many challenges that companies face in their business (Afshari, Brtka, \& Cockalo-Hronjec, 2018; Spalek, 2014). Nowadays, traditional methodologies are still used successfully; However, their application is often limited to long-term projects that take place in stable environments. Many project managers tend to apply traditional methodologies because they want to anticipate the whole project, but also because they find it difficult to give up the controls provided by traditional development and choose a methodology that is flexible (Attarzadeh, $\&$ Ow, 2008). However, for a long period of time, companies have been increasingly opting for agile methodologies as they notice improvements in various aspects such as time savings and budget savings (Charvat, 2003). The information technology industry is one of many other industries that often turn to agile methodologies (Wasileski, 2005). The most commonly used agile methodologies are as follows (Charvat, 2003; Wasileski, 2005; Schwalbe, 2016; Tumbas, \& Matkovic, 2006):

- eXtreme Programming (XP);
- Feature-Driven Development (FDD);

- Adaptive Software Development (ASD);

- Scrum;

- Crystal methodology;

- Dynamic Systems Development Methodology (DSDM);

- Rapid Application Development (RAD);

- Adaptive software development;

- Lean development.

Successful implementation of project methodology is a project itself. However, research from the early 20th century (Howes, 2001) notes that many of the methodologies used at that time were either wrong or not fully implemented. Wrong methodology can lead to chaotic project management (Fowler, 2001), which is why it is very important to carefully select methodology for each project.

Project management theory and practice provide a number of practical methodologies for effective project management. However, the main problem is that they are usually proposed regardless of the type of project, although it is clear that there are differences between the structures of certain project groups. Although in recent years organizations have been developing, adopting, adapting and applying methodologies in accordance with the needs of organization and project itself, organizations still suffer great pressure due to the need to continuously work on evaluation in improving methodologies (Dicks, 2000). Accordingly, the methodology should be chosen depending on the uniqueness and type of project, management philosophy and organizational culture (Besner, \& Hobbs, 2012; Drob, \& Zichil, 2013). However, it is important for organizations to first of all choose whether they want to apply external, already developed methodologies or want to deal with their internal development. Many organizations apply project methodologies from external sources, but with certain adaptations given that the project life cycle varies from organization to organization. On the other hand, there are various criteria by which they can be selected. According to (Charvat, 2003; Howes, 2001) methodology should be selected based on the following criteria:

- Team size. Methodologies are directly related to team size, which is why simple methodologies are proposed for smaller teams, while more complex methodologies are proposed for larger teams. 
- Budget. The budget has a big role in the project itself, which is why methodology to be used is very importan.

- Technology. Technology influences the choice of methodologies in the way that unknown technology slowing down the process of selection of methodology, considering the need to simulate and test new technologies

- Tools and techniques. Some methodologies require more tools and techniques than others. For example, for some projects it is necessary to use tools for visual modeling, database design and the like, while some projects do not require any tools.

- Criticality of the project. Critical projects with fixed deadlines must start with a well-chosen methodology. A good choice of methodology reduces the chance that the project manager will lose control.

- Existing processes. Maturity and ease of use of existing project processes greatly influences the choice of methodology. Some processes can be completely unreliable slowing down the performance of tasks.

The role of methodologies in project management creates a number of challenges for many organizations. Although each methodology offers a series of procedures and guidelines for its successful application in practice, very little attention is paid to the way in which different technologies can contribute to its application (Patel, 2009). As presented, technologies are one of the criteria by which the selection of an appropriate methodology for a project can be made, however, and the selection of technology can be adapted to the desired methodology (Charvat, 2003; Pajares et al., 2017; Zoric, Makitan, \& Brtka, 2021). What is crucial in the selection is that the use of the right technologies can significantly help to improve the implementation of the project, which is why special attention is paid to the study of this aspect of project management.

\section{RESEARCH METHODOLOGY}

\section{Research Problem, Subject and Goals}

Industry 4.0 brings with it revolutionary changes that significantly affect all aspects of human life. For business organizations, taking advantage of positive effect of these changes it means accepting its key drivers - modern technologies. To this end, organizations invest significant resources in technologies recognized as significant for the business. A review of the literature found that research in this area recognizes technologies as drivers of change, the application of which has a positive impact on the implementation and management of projects, but assuming that the right technologies are selected and used in the right way. However, the literature also shows that there is little knowledge about the contribution of Industry 4.0 technology to the success of projects.

Given the technological advances and the recognized importance of the application of technologies in project management, the question arises whether the technologies of Industry 4.0 can solve the problem of failure of IT projects. This question is the main motivator for writing this paper and conducting research on this topic. Specifically, the subject of this research is focused on the analysis of possibilities of application of modern technologies in the management of IT projects, with the intention that they contribute to the success of IT projects. In practice and in the literature, a whole range of Industry 4.0 technologies can be found, however, this paper and the accompanying research are focused on selected technologies: Cloud Computing, Internet of Things (IoT) and artificial intelligence. The research was conducted within the IT sector in Serbia. The results of this research will examine whether there is a link between the selected technologies and the success of IT project and how the success of the project can be increased based on that.

The aim of this paper is to form conclusions based on the results of empirical research and develop knowledge that will provide guidelines for improvement of project management practices in the IT sector of Serbia. Specifically, the goal is to draw conclusions about project management practices and possible guidelines for their improvement based on the data collected from the population of project managers and technical team members involved in project management activities in the Serbian IT sector. This research intends to investigate the use of modern technologies and the success of IT projects, as well as the question of their connection and thus contribute to understanding the impact that the observed modern technologies have on the success of IT projects. In addition, this paper aims to provide a scientific contribution and thus expand 
the scientific literature in the field of IT project management.

\section{Research Hypotheses}

Based on the presented problem and set goals, research hypotheses can be defined:

$H 1$ - Project managers and technical team members slightly apply modern technologies in project management in the IT sector of Serbia;

H1.1 - Project managers and technical team members slightly apply cloud-based technologies in project management in the IT sector of Serbia;

$H 1.2$ - Project managers and technical team members slightly apply Internet of Things technologies in project management in the IT sector of Serbia;

$H 1.3$ - Project managers and technical team members slightly apply artificial intelligence technologies in project management in the IT sector of Serbia.

$H 2$ - Project managers and technical team members largely recognize that modern technologies contribute to the success factors of projects in the IT sector of Serbia;

H2.1 - Project managers and technical team members largely recognize that cloud technologies contribute to the success factors of projects in the IT sector of Serbia;

$H 2.2$ - Project managers and technical team members largely recognize that Internet of Things technologies contribute to the success factors of projects in the IT sector of Serbia;

$H 2.3$ - Project managers and technical team members largely recognize that artificial intelligence technologies contribute to the success factors of projects in the IT sector of Serbia.

\section{Research Methods, Tools and Techniques}

Research conducted in the area of business represents application of scientific methods in the search for the truth about particular business phenomenon. This process includes: development of ideas and theories, problem definition, data collection, analysis and making research conclusions and implications. The structure of this research is based on the research onion systematic, proposed by (Saunders, Thronhill, \& Lewis, 2009).
Since this research requires data collection from a large population, and the researchers want to achieve a high degree of replication, a positivist $r$ approach to the research was chosen. The positivist approach considers work with measurable social reality, with researchers conducting structured, repeatable research that provides factual data. The application of positivism is an effort to apply scientific methods in the social sciences, and is most often used in combination with quantitative data collection. In addition to the positivist approach, this research has a deductive approach to testing the validity of the research hypotheses set. A deductive approach to research makes it possible to develope theories and hypotheses that are tested through empirical research.

For the purposes of this research, a method called Quantitative Mono Method, which represents data collection using a single technique, was chosen. Specifically, this research is a form of quantitative research since it applies quantitative methods to collect data and establish relationships between research variables. Quantitative methods were selected to allow access to a large group of respondents and thus enable gaining a broader picture of this topic.

The research implies the application of a survey developed on the basis of a literature review in this area. There are several ways to collect data through surveys, such as telephone conversations, sending e-mail or mail, as well as through interviews. For the purposes of this research, a questionnaire distributed electronically, via e-mail and using social networks was created. The questionnaire was created by online questionnaires application named QuestionPro (https://www.questionpro.com/). The survey was conducted with the intention to make it possible to test of hypotheses, through the review and analysis of the collected data.

\section{Creation of Questionnaire}

The questionnaire is structured so that it consists of 22 main questions of open or closed type, which are divided into sub-questions. The questions were selected based on a literature review and hypotheses set.

After the introductory note for potential respondents, there are questions 1 and 2 referring to demographic characteristics of the respondents. These include questions about gender and age of the respondents. These questions were asked with the intention to check if there are some data 
matching each other in different groups of the respondents.

Questions 3 and 4 are about the work experience of the respondents. Question 3 checks the current working area of the respondent and question 4 checks the position/job where the respondent is currently working. These questions were asked with the intention to check how many respondents are currently working in the IT industry, with the aim to check the representativeness of the sample.

Question number 5 was formed with the intention to check the most common role of the respondents in the project team. Five offered responses were formed: project manager, portfolio manager, technical team member, administrative team member and sponsor. The respondents were also allowed to enter an option that was not provided in answers.

Questions 6 and 7 are numerical questions. The respondents were expected to answer question 6: how many years of experience do they have in IT project management activities regardless of the position/job they hold and 7: how many different projects did they work on IT project management activities. These issues ware eliminating. Since the respondents are allowed to enter a value of 0 if this is the correct answer, it is possible to eliminate answers of the respondents who have no experience in terms of IT project management.

Questions number 8 and 9 check whether the respondent has a certificate in the field of IT project management, as well as the type of certificate possessed. These questions check the reason for the certification of the respondents. Question number 8 was formed as a question with the offered answers, but also the possibility of the respondents to enter an answer independently if they have one of the certificates that was not offered. Question number 9 is in the form of an open-ended question, with the possibility to leave it without any answer.

Question number 10 is an open-ended question asked with the intention that the respondents initially state the tools and technologies they apply in any IT project management activities. Comparing the answers to this question with the answers to other questions, it is expected that it can be seen whether the respondents understand the topic being discussed.
Questions 11, 13 and 15 refer to closed-ended questions with a limited number of offered answers. The respondents are expected to reply with YES or NO in order to indicate whether they use specific technologies in IT project management activities. Question number 11 refers to cloud technologies, question 13 to IoT technologies, while question 15 refers to artificial intelligence technologies.

Questions 12, 14 and 16 are accompanying questions related to the previous three questions. These are open-ended questions in which the respondents are expected to list the specific tools, devices and technologies they use, considering that they are from the group of artificial intelligence, cloud or IoT tools, devices and technologies. This question was asked in order to compare with question number 10, to determine whether the respondents are able to classify tools and technologies into three observed groups.

Question number 17 is a question with 20 subquestions, and the respondents are expected to rate on a scale from 1 to 5 the extent to which they apply certain technologies. The first 5 subquestions relate to cloud technologies, the next 10 sub-questions relate to artificial intelligence technology, and the last 5 sub-questions relate to IoT technologies. These technologies are derived from a detailed review of several literature sources presented in the literature review. The scale of answers had values from 1 to 5 offered as follows: 1 - I never use; 2 - I rarely use; 3 - sometimes I use; 4 - I use often; 5 - I always use.

Question number 18 is an open-ended question and checks the reasons why the respondents do not apply the technologies offered in the previous question.

Questions 19, 20 and 21 expect the respondents to determine on a scale of 1 to 5 the extent to which they agree that the observed technologies provide assistance in certain aspects of IT project management. Each of these issues looks at a group of technologies - cloud, IoT and artificial intelligence. For project management aspects, project success factors defined by (Slevin, \& Pinto, 1986) were taken. The scale has values from 1 to 5 as follows: 1 - I do not agree much; 2 - I do not agree; 3 - I am indecisive; 4 - I agree; and 5 - I agree to a large extent. 
The last question, question number 22, is a closedended question with the possibility for the respondents to answer choosing one or more offered answers. The respondents are expected to assess how the last completed project was completed or, if not completed, how they anticipate it will be completed. The offered observation of the project success, ware based on the measures provided by (Pinto, \& Prescott, 1990). The authors of this model of success criteria define 12 options for observing the success of the project, of which 3 represent individual success criteria (time, costs and satisfaction), while the rest can be reduced to three more criteria (performance, effectiveness and usability). Since the respondents give YES or NO answers to this question, the researchers will consider that two out of three possible positive answers within one group mean that the criterion is positively evaluated, while two negative and one positive out of three possible mean that the criterion is negatively evaluated. In case the project was not completed or will not be completed successfully, the respondents were able to choose the answer "none of the offered" and thus mark the project as unsuccessful.

Asking closed-ended questions with offered answers made it possible to reduce dispersion and find a link between technology and project success. Open-ended questions were not mandatory, and asking them provided a better understanding of other respondents' answers.

\section{Research Sample}

Non-probability research sampling method was chosen for sample creation in this research. Specifically, a combination of different methods was used, such as: the convenience sampling method, the snowball method, the voluntary response sampling method, and the purposive sampling method. The population for this research consists of all project, program and portfolio managers, as well as of all technical team members who have experience in performing project management activities.

This sample is a representative for the IT sector of Serbia, considering that the potential respondents were selected from the entire territory of Serbia, and not only from a certain geographical area. During the sampling, the representatives of various companies are targeted, more precisely smaller and larger companies, as well as freelancers who perform their activities from the territory of Serbia.
In addition, the potential respondents with different years of work experience are targeted.

The total sample size is 199 respondents, of which $51 \%$ are men, while $49 \%$ are women. Also, the youngest respondents are 22 years old, while the oldest are 64 years old, and the largest group of respondents are those who are 33 and 34 years old. All the respondents (100\% of the sample) state that they have experience in managing IT projects. Specifically, the sample includes the respondents with a minimum of one year of work experience in these activities, while most of them have 33 years of work experience.

\section{RESEARCH ANALYSIS}

\section{Use of Technologies}

Regarding the specific tools and technologies that the respondents use in IT project management activities, it was found that 82 different software tools for project management are used, emphasizing that this list is not complete and many other software are used. All identified tools are commercial since the respondents did not list the internally developed tools they apply. Among the most used tools there are: Jira software used by approximately $62 \%$ of the sample, MS Project used by approximately $47 \%$ of the sample and Trello used by approximately $34 \%$ of the respondents. Users of other software tools do not participate in the sample and more than $30 \%$ are observed for each listed tool separately.

Regarding the observed technologies of Industry 4.0 in IT project management activities, it was found that $62 \%$ of all the respondents use cloud technologies, while much less respondents use IoT and artificial intelligence technologies, more precisely less than $20 \%$ of the entire sample observed separately for each technology.

The next question refers to the assessment of the extent to which the respondents apply specific tools and devices based on the observed technologies. The questionnaire presents 20 different tools and devices, which can then be grouped into three groups based on the technologies that support them. To test the possibility of grouping these items into three dimensions, Chrombach's alpha value was calculated. This value measures the internal consistency in the group and shows whether the respondents answer all the questions within the 
group in the same way. Chrombach's alpha values range from $\alpha=0.665$ to $\alpha=0.762$.

According to Table 1, the average extent to which respondents use the offered technologies may be seen, as well as the most common assessment they gave. The respondents were asked to rate the extent to which they use the offered technologies on a scale from 1 to 5 , where 1 indicates that they never use, 2 that they rarely use, 3 that they sometimes use, 4 that they use frequently, while 5 indicates that they always use the offered technologies.

Table 1: An overview of the use of modern technologies

\begin{tabular}{|c|c|c|c|}
\hline Technologies & $\begin{array}{c}\text { Average } \\
\text { Grade }\end{array}$ & $\begin{array}{c}\text { The Most } \\
\text { Common Answers }\end{array}$ & C. alpha \\
\hline Cloud & 3.9 & & \\
\hline Cloud software for any project management activities & 3.6 & 5 & \multirow{5}{*}{0.707} \\
\hline Cloud document management systems & 2.5 & 1 & \\
\hline Cloud storage systems & 4.3 & 5 & \\
\hline Cloud tools for communication and collaboration & 4.7 & 5 & \\
\hline Online shared calendars & 4.4 & 5 & \\
\hline Artificial intelligence & 2.3 & & \\
\hline Tools for selecting a project for realization or portfolio & 2.4 & 1 & \multirow{10}{*}{0.762} \\
\hline Project monitoring and risk assessment tools & 3.1 & 4 & \\
\hline Tools for project feasibility assessment based on realized projects & 1.9 & 1 & \\
\hline Intelligent software agents & 1.4 & 1 & \\
\hline Team member selection tools & 1.5 & 1 & \\
\hline Tools for project implementation support & 3.5 & 4 & \\
\hline Tools for generating reports or documentation & 2.9 & 3 & \\
\hline Software that performs recurring tasks & 2.5 & 1 & \\
\hline Project planning assistance tools & 1.8 & 1 & \\
\hline Decision support tools based on previous projects & 1.6 & 1 & \\
\hline IoT & 2.4 & & \\
\hline Smartphones & 4.6 & 5 & \multirow{5}{*}{0.665} \\
\hline Smart watches & 2.1 & 1 & \\
\hline Smart boards & 1.9 & 1 & \\
\hline Smart camcorders & 1.6 & 1 & \\
\hline Tools for managing and monitoring connected smart devices & 1.6 & 1 & \\
\hline
\end{tabular}

In order to find out the reasons why the respondents do not use the offered technologies, an open-ended question was asked in which they stated the reasons. By resuming the reasons, it was received as follows: the respondents did not see the need for these tools, the use of these tools does not enter the domain of the position they work in, their use is burdensome and time consuming, they do not trust these tools, they have no previous experience with these types of tools, tools are unrelated and redundant, they do not see the benefit of use, use does not meet the needs of the company.

\section{Success Factors}

Figure 1 shows the average scores by which the respondents rated that they agreed that a particular technology provided support to all aspects of project management. In general, it can be noticed that all technologies were rated with an average grade, which indicates that the respondents agree that these technologies have a positive impact. The strength of their positive impact varies between technologies, so that cloud technologies have a strong positive impact, while for IoT and artificial intelligence technologies it can be said that their impact is positive, but of lower intensity.

Table 2 provides a comparative overview of the previously presented average scores by which the respondents show the extent to which they agree that each of the technologies contributes to the success of the project.

\section{Success Criteria}

The issue of project success criteria was considered through the last question of the questionnaire and can be analyzed from several 
aspects. The respondents assessed the success of the project through 12 options, as well as whether the project was generally completed successfully.

The offered options and answers of the respondents are shown in Table 3.

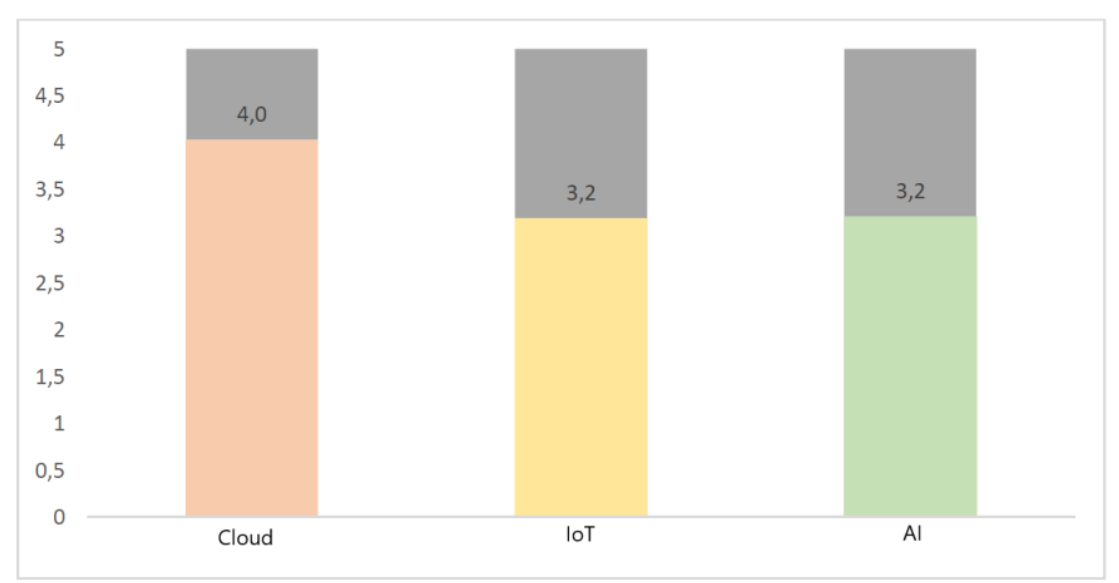

Figure 1: Review of assessments of the modern technologies influence on the success factors of IT projects

Table 2: A comparative overview of modern technologies impact on each project success factor

\begin{tabular}{|l|l|c|c|c|c|c|c|}
\hline & \multirow{2}{*}{ Success factors } & \multicolumn{3}{|c|}{ Average rating } & \multicolumn{3}{|c|}{ The most common grade } \\
\cline { 3 - 8 } & Cloud & IoT & AI & Cloud & IoT & AI \\
\hline Q1 & Understanding the project mission & 3.7 & 3.0 & 3.0 & 4 & 3 & 3 \\
\hline Q2 & Obtaining support from senior management & 3.7 & 3.1 & 3.0 & 4 & 3 & 3 \\
\hline Q3 & Compiling a project schedule and plan & 4.4 & 3.2 & 3.4 & 5 & 3 & 3 \\
\hline Q4 & Consulting with clients during project activities & 4.3 & 3.4 & 3.1 & 4 & 3 & 3 \\
\hline Q5 & Understanding project roles & 3.8 & 2.9 & 3.0 & 4 & 3 & 3 \\
\hline Q6 & $\begin{array}{l}\text { Clear definition of activities and adequate selection } \\
\text { of people and technologies }\end{array}$ & 3.9 & 2.9 & 3.2 & 4 & 3 & 3 \\
\hline Q7 & Acceptance of project results by the client & 3.8 & 3.1 & 3.1 & 4 & 3 & 3 \\
\hline Q8 & Monitoring project progress & 4.5 & 3.4 & 3.5 & 5 & 3 & 3 \\
\hline Q9 & Communication with stakeholders & 4.2 & 3.5 & 3.1 & 4 & 3 & 3 \\
\hline Q10 & Problem solving & 3.9 & 3.3 & 3.4 & 4 & 3 & 3 \\
\hline
\end{tabular}

Table 3: Overview of successfully implemented projects according to different success options

\begin{tabular}{|l|c|c|}
\hline Success assessment option & $\begin{array}{c}\text { Number of successfully } \\
\text { evaluated projects }\end{array}$ & $\begin{array}{c}\text { Percentage of } \\
\text { the sample }\end{array}$ \\
\hline 1. The project was completed on time & 125 & $63 \%$ \\
\hline 2. The project was completed within the budget & 131 & $66 \%$ \\
\hline $\begin{array}{l}\text { 3. The completed project provided a functional solution to the } \\
\text { problem for which it was done }\end{array}$ & 155 & $78 \%$ \\
\hline 4. The project result was used by the clients & 163 & $82 \%$ \\
\hline $\begin{array}{l}\text { 5. The project result has contributed to increased efficiency and } \\
\text { effectiveness }\end{array}$ & 119 & $60 \%$ \\
\hline 6. The project result is the best solution considering alternatives & 72 & $36 \%$ \\
\hline 7. Important clients benefit from the project results & 123 & $62 \%$ \\
\hline 8. I am satisfied with the project realization process & 122 & $61 \%$ \\
\hline $\begin{array}{l}\text { 9. Initial non-technical problems were overcome when users } \\
\text { accepted the project }\end{array}$ & 46 & $23 \%$ \\
\hline $\begin{array}{l}\text { 10. The project result leads to improvement, better decision making } \\
\text { or better performance in the client's work }\end{array}$ & 93 & $47 \%$ \\
\hline 11. The project result has a positive impact on those who use it & 126 & $63 \%$ \\
\hline $\begin{array}{l}\text { 12. The project result is a certain improvement in performance in } \\
\text { terms of the way clients conduct their activities }\end{array}$ & 95 & $48 \%$ \\
\hline
\end{tabular}


Based on the data in Table 3, most of the respondents rated their project as a project that provided the result used by the client $(82 \%$ of the total sample), as if their project provided a functional solution to the problem for which it was done $(78 \%$ of the total sample). The fewest projects are successful in overcoming the initial problems of non-technical type through the acceptance of the project by the clients (23\% of the sample). In general, $74 \%$ of the respondents said that the project was generally successful.

This successfulness can be reduced to the success criteria of the project. Based on the previously presented answers, the project success criteria were evaluated in the manner shown in Table 4.

Table 4: Review of project success according to the success criteria

\begin{tabular}{|l|l|c|c|}
\hline Options & Criterion & $\begin{array}{c}\text { Number of } \\
\text { successfully } \\
\text { evaluated } \\
\text { projects }\end{array}$ & $\begin{array}{c}\text { Percentage } \\
\text { of the } \\
\text { sample }\end{array}$ \\
\hline 1 & Time & 125 & $63 \%$ \\
\hline 2 & Cost & 131 & $66 \%$ \\
\hline 8 & Satisfaction & 122 & $61 \%$ \\
\hline $3,6,12$ & Performance & 106 & $53 \%$ \\
\hline $5,10,11$ & Effectiveness & 108 & $54 \%$ \\
\hline $4,7,9$ & Use & 126 & $63 \%$ \\
\hline
\end{tabular}

According to the presented results, it can be noticed that approximately the same number of the respondents assessed that the project was successful according to each criterion. Most of the respondents $(66 \%)$ rated the project as successful in terms of costs, while the fewest respondents $(53 \%)$ rated the project as successful in terms of performance.

Since the respondents indicated whether the same project was generally successful, it is possible to analyze the overall performance according to the performance in a certain criterion. The analysis of the data showed that the respondents who assessed that the project was generally successful also assessed that the project was successful in terms of one or more criteria.

The analysis of project success according to each criterion can be observed from the aspect of the technologies they use. Based on whether the respondents stated that they used industry 4.0 technologies or not, it is possible to see the success of the project. A separate analysis was done for each technology, which shows what percentage of the respondents who use these technologies evaluate their project as successful, as well as what percentage of the respondents who do not use them think that their project was successful. The results of the research showed that the respondents who use cloud technologies, IoT, as well as the technologies of artificial intelligence in a larger number evaluate that their project is generally successful than the respondents who do not use these technologies.

\section{DISCUSSION}

The data from the conducted research indicate that the respondents, experts in the field of IT project management in Serbia, apply different technologies in their activities. More precisely, in the statements of the examined experts, it was identified that more than 82 different software tools are used in IT project management activities in Serbia, as well as that the number of 82 tools is not final because the respondents emphasize that they use more than the listed tools. The suitability of the identified tools for application in project management activities was also supported by research conducted by (Chadli et al., 2016). Specifically, some of the tools identified by (Chadli et al., 2016), have also been identified in the practice of IT project management in Serbia.

Since the general application of technologies does not include the application of Industry 4.0 technology, the question arises to what extent experts in the field of IT project management in Serbia apply modern technologies such as: cloud, Internet of Things and artificial intelligence. Accordingly, it was initially analyzed how many respondents apply these technologies in general in the mentioned activities, and then to what extent they apply them. Based on the analysis, it was established that a large number of the respondents apply cloud technologies, while for artificial intelligence and IoT technologies this is not the case in practice.

When asked to what extent they use them, a similar division has been established where cloud technologies are applied to a large extent while other modern technologies are applied to a small extent. Based on this, it can be concluded that cloud technologies have found application in the management of IT projects in Serbia, while for technologies of artificial intelligence and IoT this is not the case. In part, these results are supported by a survey of project management practices in 
Serbia conducted in 2012 (Milin, 2013), which suggests that software tools are generally poorly used in project management activities. The previously established weak application of any form of software tools has led to the fact that it is not surprising that there is a slow acceptance of tools based on modern technologies.

However, more intensive application of cloud technology tools indicates the ability of this area to respond to changes and thus the potential for modern technologies to be applied to a greater extent in the future. However, greater acceptance of cloud technologies can only be a consequence of the environment in which projects are implemented, given that these projects are implemented in the IT sector, while previous research looks at projects that are implemented in several different sectors. Such results may be a consequence of greater awareness of the project manager and members of the project team about the global importance of information technology, given that the projects they implement for the result include information technology.

It is interesting to observe the extent to which individual technologies and devices are applied within these three groups of modern technologies. What can be noticed is that, unlike other cloud technologies that are applied to a large extent, cloud document management systems are applied to a negligible extent. This practice may be a consequence of redundancy in technology capabilities and the possibility that other technologies can meet all user needs, which is why users no longer think about implementing a cloud document management system. The opposite situation occurs within the group of IoT technologies, where the application of all devices and tools is poorly evaluated except for the application of smartphones. This assessment is not unexpected given the widely known widespread use of smartphones, both in private and business life. However, the large degree of smartphones application is not enough for conclusion that application of IoT technologies may be considered to be widely represented in general. Variations in the application of individual technologies can also be observed within the group of artificial intelligence technologies, however, these variations are not as intense and unique as in the other two groups.

Based on the previous conclusions on the application of modern technologies, sub- hypothesis $\mathrm{H}-1.1$ is rejected, while sub-hypotheses $\mathrm{H}-1.2$ and $\mathrm{H}-1.3$ are accepted. This suggests that the first major hypothesis $\mathrm{H} 1$ of this study may be partially accepted. In other words, modern technologies are partially applied by project managers and technical team members in project management within the IT sector of Serbia. Partial application is reflected in the fact that cloud technologies are applied to a greater extent, and artificial intelligence and IoT technologies to a lesser extent.

The issue of modern technologies influence on the project success factors is considered through the support that these technologies provide in various aspects of project management. According to the results of this research, it can be noticed that experts in this field believe that all three technologies have a positive impact on different aspects of IT project management, however, the intensity of their impact varies among these technologies. Cloud technologies are recognized as technologies that achieve the highest intensity of positive impact, while for other technologies, a positive impact of lower intensity can be observed.

Cloud technologies are recognized as technologies the use of which has a positive impact on all aspects of project management viewed through success factors. One of the biggest positive impacts of these technologies was recognized from the aspect of consulting with clients during project activities and communication with stakeholders. However, an even greater positive impact of these technologies was recognized from the aspect of project scheduling and project monitoring. Such results are not unexpected given that numerous studies (Asava \& Mzee, 2010; Francke \& Weideman, 2012; Khan, et al., 2011; Mlitwa \& Pekane, 2015; Sloniec, 2015) suggest that the cloud technology is primarily used to achieve cooperation, communication, coordination, as well as the exchange of information about the project and the exchange of resources within the project. It is interesting to note that in the practice of IT project management in Serbia, the impact of these technologies on other aspects of project management involving clients is recognized, such as the acceptance of project results by clients. These results can be related to the fact that in most cases IT projects are based on agile methodologies that focus on achievement of cooperation with clients and their involvement in the project management process. According to the research results, a strong positive influence of cloud 
technologies on problem solving factors, clear definition of activities and adequate selection of people and technologies, as well as understanding of the roles in the project are recognized. These aspects are closely related to the issue of team collaboration and the issue of team management, which is why these results are also not surprising given that cloud technologies are in the literature (Asava \& Mzee, 2010; Francke \& Weideman, 2012; Khan, et al., 2011; Mlitwa \& Pekane, 2015; Sloniec, 2015) recognized as technologies that provide support in cooperation of team members, especially when it comes to virtual teams.

Internet of Things technologies are recognized in the practice of IT project management in Serbia as technologies that are important in various aspects of project management. Their positive impact was recognized in terms of the application of these technologies in communication with stakeholders, consulting clients during project activities and monitoring project progress. These results are not surprising given that these technologies, as well as the cloud, have been recognized in the literature (Andrei, Ioan, \& Florin, 2018; Hu, Yuan, \& Zhang 2009; Lou, et al., 2011) as technologies that provide great support to all stakeholders and team members throughout the project life cycle, as they enable cooperation to be achieved at any time. However, recognition of importance of these technologies to a lesser extent than cloud technologies can be attributed to the fact that these technologies are not applied in practice as much as the cloud. Given this, it is expected that their importance will be recognized to a greater extent when IoT technologies themselves are applied to a greater extent.

Artificial intelligence is recognized as a technology that on average has the same impact on various aspects of IT project management as IoT technology. However, its positive impact is manifested in other aspects. It is recognized that these technologies have the greatest positive impact on project scheduling and planning, project monitoring, and problem solving. In addition, this technology has a positive impact on the clear definition of activities and adequate selection of people and technology. Such results are also not unexpected, given that these technologies have been recognized in the literature (Chou \& Lin, 2015; Pireto, 2019; Wang, 2019) as technologies that provide support in the observed aspects of management. The ability to apply this technology in activity automation, budget estimation, predictive implementation analysis, risk identification, or as decision support, are the same aspects in which this technology is recognized as significant. The positive impact on other aspects of project management is not so pronounced as this technology does not have a primary purpose to support these aspects. However, an indirect impact of this technology on other aspects is recognized to a significant extent. In other words, it is not recognized from any aspect that this technology does not have a positive impact. If this technology were analyzed only from the specific aspects for which it is intended, its general positive impact on the field of project management would be recognized to a greater extent.

According to the previously presented analysis of positive impact that these technologies have on various aspects of project management, the second main hypothesis H-2 is accepted. This hypothesis is accepted since sub-hypothesis H-2.1 is fully accepted and the other two sub-hypotheses are partially accepted. Sub-hypothesis H-2.2 and subhypothesis H-2.3 are partially accepted since positive impact of IoT and artificial intelligence technology is recognized to a lesser extent than is the case of H-2.1. However, positive impact of IoT and artificial intelligence technologies cannot be ignored because both technologies show a pronounced impact in those aspects that are recognized in the literature as the primary purposes for use of these technologies.

A special aspect of this research is aimed at examination of criteria of success in project management in the IT sector of Serbia. The results of this research indicate that a large number of IT projects in Serbia are recognized as successful according to various success criteria. However, the intensity of success according to the criteria was not measured, but only the number of the respondents who believe that their project was successful according to some criteria was observed. Also, this research examines how many projects that are assessed as generally successful are considered successful according to some criteria. Such an analysis established that all successfully evaluated projects in approximately equal numbers were evaluated as successful according to individual criteria. Nevertheless, it can be noticed that the most successful projects were evaluated as successful in terms of implementation within the planned costs. What 
these results suggest is that all success criteria are approximately equally important for professionals who believe that their projects have been generally successful.

The way in which the examined experts view the issue of project success according to the criteria can be analyzed separately from the point of view of application of the observed technologies of Industry 4.0. The respondents who use any of the observed modern technologies in majority identify that their projects have been successful, while the percentage of increase in successfully identified projects varies from technology to technology. The respondents who apply cloud technologies in majority estimate that their projects were successful according to every criterion, while this is not the case with experts who use IoT and artificial intelligence technologies. Specifically, when the respondents use cloud, IoT or artificial intelligence technologies, in all three cases they assess that their project was successful in terms of implementation within the planned time. Also, the respondents who use cloud, IoT or artificial intelligence technologies, in all three cases, evaluate their projects as successful in terms of usability, and in terms of effectiveness. Usability refers to the creation of a result (1) that is later used by the client, (2) that benefits the client, and (3) that the client will accept at the end of the project itself. Effectiveness refers to the fact that a project provides a result that has (1) direct benefits, (2) a positive impact on those who use it and (3) leads to improvements in the clients' decisionmaking process. On the other hand, the respondents who use cloud or artificial intelligence technologies in both cases evaluate their projects as successful both in terms of performance criteria and in terms of satisfaction criteria. The performance criterion refers to the creation of project results that provide a functional solution and improvements in client's performance. The criterion of satisfaction refers to the fact that they are much more satisfied with the overall progress of the project. However, in terms of implementation criteria within the planned costs, it can be noticed that only the respondents who use cloud technologies in majority believe that their project is successful compared to those who do not use cloud technologies. Given that modern technologies were previously recognized as technologies that have an impact on various success factors of the project, it is not unexpected that research results show that the respondents who use these technologies in majority assess that their projects are more successful in terms of different success criteria compared to experts who do not use the observed technologies.

\section{CONCLUSIONS AND IMPLICATIONS}

Upon examination of the practice of project management, it can be noticed that a large percentage of IT projects are completed successfully in the IT sector of Serbia. Observation of success through different criteria found that each criterion has approximately equal significance when talking about successful projects. However, the results of the research indicate that in the IT sector of Serbia, out of all successful projects, it was rated the most successful in terms of implementation within the planned time. Observation of project success from the aspect of application of modern technologies found out that experts who apply certain technologies evaluate projects more successfully than experts who do not apply them. Upon observation of the respondents from the aspect of the application of cloud, IoT or artificial intelligence technologies, it was found that those who use any of these technologies evaluate their projects in majority as generally successful. In addition, when experts apply modern technologies, differences that occur in success assessments depending on individual success criteria can be noticed. These differences are mostly positive, suggesting that, unlike the respondents who do not use modern technologies, the respondents who use them in majority evaluate their projects as successful according to various criteria. Based on these conclusions, some of the future research may be aimed at examination of intensity of differences in project performance assessments that occur when experts in this field begin to apply modern technologies.

The conducted research contributes in the way that it points out to possible areas for improvement of project management practices through the inclusion of modern technologies in various management activities. First of all, this research shows, that there is a potential for modern technologies to be applied in the field of project management. However, this potential in the Serbian IT sector has not been fully exploited. Given that experts in this field recognize that modern technologies are important for various aspects of project management, it is expected that taking advantage of the possibilities of applying this technology will lead to better results in the success of IT projects. Such expectations are 
justified, given that it is recognized that experts who already use these technologies evaluate their projects as generally successful to a greater extent, but also as successful according to various criteria. Although this research provided a greater insight into the field of the IT project management in Serbia, based on this research, the directions of future research can be identified. First of all, future research can be focused on the general population within project management. In this way, it would be possible to conduct comparative research that would allow a better understanding of project management practices comparing results between different industries. Further research may be concerned with study of the same issue from the perspective of different participants in the project management process, with additional importance being placed on the perspective of project stakeholders. Given that the IT industry is increasingly based on agile methodologies that involve stakeholders in various activities during project management, conducting such research would contribute to understanding of importance of these technologies from the perspective of key project participants. The third direction of future research may be aimed at examination of reasons why certain technologies within the same group of technologies are more used in project management. Such research can contribute to a deeper understanding of modern technologies themselves and their application in this field. Based on this research, the fourth direction of future research can be focused on further examination of changes that occur in project performance evaluations based on whether modern technologies are applied in project management. Such research can be conducted on two samples, one involving those who use these technologies and the other involving those who do not. Examination of the way in which both groups view successful projects can identify differences in the perspectives of observing this area. Finally, an additional direction of future research may be directed at examination of success of the project from the perspective of other modern industry 4.0 technologies. Since this research focuses on three Industry 4.0 technologies only, such research would enrich the understanding of how modern technologies can be applied in this area and contribute to the success of the project.

\section{ACKNOWLEDGEMENT}

This research is financially supported by the Ministry of Education and Science of the Republic of Serbia under the project number TR32044: The Development of Software Tools for Business Process Analysis and Improvement, 2011-2021.

\section{REFERENCES}

Afshari, A. R., Brtka, V., \& Cockalo-Hronjec, M. (2018). Project risk management in Iranian software projects. Journal of Engineering Management and Competitiveness (JEMC), 8(2). Serbia: The Mihajlo Pupin Technical Faculty, Zrenjanin.

Andrei, G., Ioan, F., \& Florin, D. (2018). A new vision over Agile Project Management in the Internet of Things era. Procedia - Social and Behavioral Sciences, 238, 277-285. https://doi.org/10.1016/j.sbspro.2018.04.003

Asava, R.. \& Mzee, H. (2010). Cloud Computing meets Project Management. PM World Today, 12(6).

Attarzadeh, I.. \& Ow, S. H. (2008). Modern Project Management: Essential Skills and Techniques. Communications of the IBIMA, 2, 1-9.

Besner, C., \& Hobbs, B. (2012). An Empirical Identification of Project Management Toolsets and a Comparison among Project Types. Project Management Journal, 43(5), 24-46. https://doi.org/10.1002/pmj.21292

Chadli, S. Y. et al. (2016). Software project management tools in global software development: a systematic mapping study. Springer Plus, 5(1). https://doi.org/10.1186/s40064-016-3670-7

Charvat, J. (2003). Project Management Methodologies: Selecting, Implementing, and Supporting Methodologies and Processes for Projects. Canada: John Wiley \& Sons, Inc.

Chou, J. S., \& Lin, C. W. P. A. D. S. J. Y. (2015). Optimized artificial intelligence models for predicting project award price. Automation in Construction, 54, 106-115. https://doi.org/10.1016/j.autcon.2015.02.006

Dicks, R. S. (2000). The Paradox of Information. Control Versus Chaos in Managing Documentation Projects with Multiple Audiences. Proceedings of 18th annual ACM International Conference on Computer Documentation. MA, USA, Technology $\&$ Teamwork Cambridge.

Drob, C., \& Zichil, V. (2013). Overview regarding the main guidelines, standards and methodologiesused in project management. Journal of Engineering Studies and Research, 19(3), 26.

Fowler, M. (2001). The New Methodology. Wuhan University Journal of Natural Science, 6(1-2), 1224. https://doi.org/10.1007/BF03160222

Francke, E., \& Weideman, M. (2012). Adopting disruptive technologies by managing projects in the cloud. Durban, South Africa, Cape Peninsula University of Technology.

Howes, N. R. (2001). Modern Project Management Successfully Integrating Project Management 
Knowledge Areas and Processes. New York, American Management Association PresS.

Hu, Z., Yuan, Q., \& Zhang, X. (2009). Research on Agile Project Management with Scrum Method. Proceedings of 2009 IITA International Conference on Services Science, Management and Engineering. Zhangjiajie, China, IEEE.

Khan, A., Shaikh, P., Dhembre, C., \& Gawali, S. (2011). Cloud Services for Collaborative Web Based Project Management System. International Journal of Computer Science Issues, 8(6), 180-184.

Lou, P., Liu, Q., Zhou, Z., \& Wang, H. (2011). Agile Supply Chain Management over the Internet of Things. Proceedings of 5th International Conference on Management and Service Science (MASS). Wuhan, China, IEEE.

Milin, D. (2013). Project management software tools as a mean for assuring projects's success. U: D. Bulatović, L. Bulatović \& O. Arsenijević, editors, Knowledge, Education, Media. Sremski Karlovci: Faculty of Management, 74-87.

Mlitwa, N., \& Pekane, A. (2015). Technology innovations and cloud computing in project management: an analysis of the academic and industry perspectives in Cape Town, South Africa. Seville, Spain.

Pajares, J., Poza, D., Villafanez, F., \& Lopez-Paredes, A. (2017). Project Management Methodologies in the Fourth Technological Revolution. U: C. Hernández, ur. Advances in Management Engineering. 121-144. Cham: Springer.

Patel, K. (2009). Information technology in using project management methodologies. Proceedings of PICMET '09 Conference: Technology Management in the Age of Fundamental Change. Portland, OR, USA, Portland International Center for Management of Engineering and Technology.
Pinto, J. K., \& Prescott, J. (1990). Planning and Tactical Factors in the Project Implementation Process. Journal of Management Studies, 27(3), 305-327.

Pireto, R. (2019). Impacts of Artificial Intelligence on Management of Large Complex Projects. PM World Journal, 8(5), 1-20.

Saunders, M., Thornhill, A., \& Lewis, P. (2009). Research Methods for Business Students. 5th ur. Harlow: Pearson Education Limited.

Schwalbe, K. (2016). Information Technology Project Management, Revised. 8th ur. Boston, MA: Cengage Learning.

Slevin, D. P., \& Pinto, J. K. (1986). Project implementation profile: new tool for project managers. Project Management Journal, 17(3), 5770 .

Sloniec, J. (2015). Use of Cloud Computing in Project Management. Applied Mechanics and Materials, 791, 49-55.

Spalek, S. (2014). Finding a New Way to Increase Project Management Efficiency in Terms of Time Reduction. Engineering Economics, 25(5), 538-548.

Tumbas, P., \& Matković, P. (2006). Agile vs Traditional Methodologies in Developing Information Systems. Management Information System, 1(2006), 15-24.

Wang, Q. (2019). How to apply AI technology in Project Management. PM World Journal, 8(3), 1-12.

Wasileski, J. S. (2005). Learning Organization Principles \& Project Management. Proceedings of the 33rd Annual ACM SIGUCCS Conference on User Services 2005. Monterey, CA, USA, Association for Computing Machinery.

Zorić, T., Makitan, V., \& Brtka, E. (2021). Modern technologies in IT project management. Proceedings of the XI International Symposium Engineering Management and Competitiveness - EMC 2021, Technical Faculty "Mihajlo Pupin” Zrenjanin, Serbia.

\section{UTICAJ MODERNIH TEHNOLOGIJA NA FAKTORE USPEHA PROJEKATA U IT SEKTORU SRBIJE}

S obzirom na tehnološki napredak i prepoznat značaj primene tehnologija u upravljanju projektima, postavlja se pitanje da li tehnologije Industrije $4.0 \mathrm{mogu}$ da reše problem neuspeha projekata informacionih tehnologija (IT). Ovo pitanje je glavni motivator za pisanje ovog rada i sprovođenje istraživanja na ovu temu. Ovaj rad opisuje istraživanje koje je sprovedeno sa namerom da se ispita u kojoj meri savremene tehnologije mogu doprineti uspehu IT projekata. Istraživanje pokazuje u kojoj meri se savremene tehnologije primenjuju u upravljanju projektima u IT sektoru Srbije, kao i u kojoj meri stručnjaci smatraju da ove tehnologije pozitivno utiču na uspeh projekta, analizirajući to pitanje kroz njihov uticaj na faktore uspeha. Ovo istraživanje pruža uvide koji mogu doprineti boljem razumevanju savremenih tehnologija i njihove primene u praksi.

Ključne reči: IT projekti; Upravljanje IT projektima; Faktori uspeha projekata; Tehnologije Industrije 4.0. 